\title{
Erratum to: Effect of sucrose on shoot regeneration in Agrobacterium transformed Hypericum perforatum L. roots
}

Branka Vinterhalter ${ }^{1} \cdot$ Snežana Zdravković-Korać ${ }^{1} \cdot$ Nevena Mitić $^{1} \cdot$

Borut Bohanec $^{2} \cdot$ Dragan Vinterhalter $^{1} \cdot$ Jelena Savić $^{1}$

Published online: 1 October 2016

(C) Franciszek Górski Institute of Plant Physiology, Polish Academy of Sciences, Kraków 2016

\section{Erratum to: Acta Physiol Plant (2015) 37:37 DOI 10.1007/s11738-015-1785-Z}

The corresponding author of this paper, Jelena Savić, has acknowledged that she manipulated two bands in Fig. 5c. The original figure is given here. The modification does not alter the interpretation of the data in any way. The author sincerely regrets the mistake and would like to apologize to her co-authors, the editors and readers.

The online version of the original article can be found under doi:10.1007/s11738-015-1785-z.

\section{Jelena Savić}

savic.jelena@ibiss.bg.ac.rs

1 Institute for Biological Research "'Siniša Stanković", University of Belgrade, Bulevar Despota Stefana 142, 11060 Belgrade, Serbia

2 Biotechnical Faculty, University of Ljubljana, Jamnikarjeva 101, 1000 Ljubljana, Slovenia

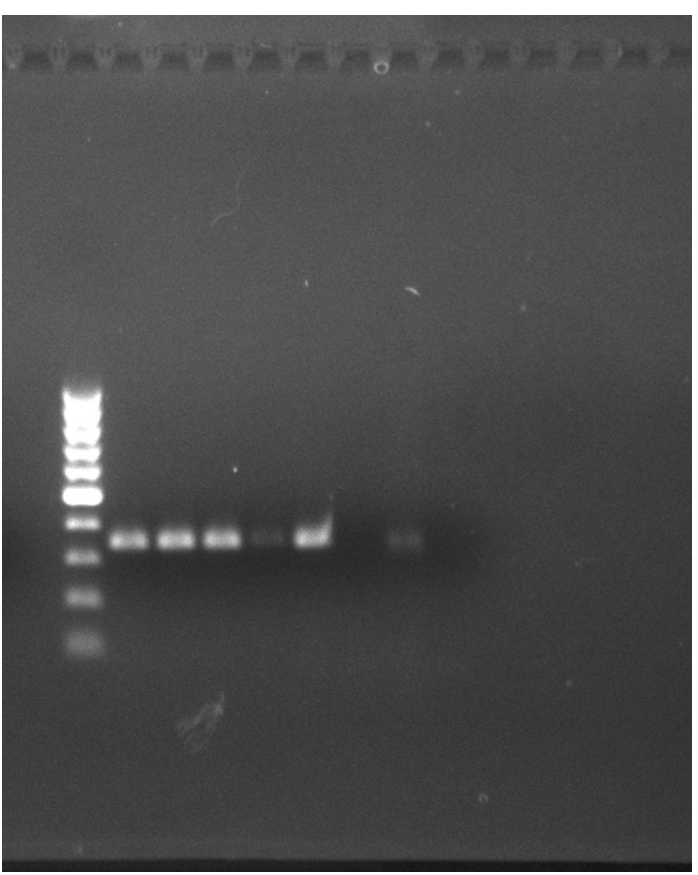

